\title{
Studying Illegal Online Trades in Plants: Market Characteristics, Organisational and Behavioural Aspects, and Policing Challenges
}

\author{
Anita Lavorgna ${ }^{1}$ (D) Maurizio Sajeva ${ }^{2}$ \\ Published online: 15 May 2020 \\ (C) The Author(s) 2020
}

\begin{abstract}
Illegal commerce in plants and their derivatives threatens and destroys numerous species and important natural resources, and may cause phytosanitary and health problems. This illegal trade, which has been boosted by the commercialisation of the Internet, has been relatively overlooked in criminological research. Furthermore, the policing of illegal plant markets remains limited and poorly resourced, with law enforcement agencies lacking awareness and technical capacity in investigation and prosecution services. Based on semi-structured interviews with law enforcement officers and other relevant experts, this study, developed in the context of the ESRC-funded project "FloraGuard: Tackling the illegal trade in endangered plants" offers an analysis of the characteristics of illegal online trading in plants and of the actors operating therein, of current policing practices, and identification of the main challenges to be addressed to better assist law enforcement. It concludes by offering practical recommendations to curb this illegal market.
\end{abstract}

Keywords Wildlife trafficking $\cdot$ Illegal plant trade $\cdot$ Environmental crime $\cdot$ Policing · Recommendations $\cdot$ Interdisciplinarity

Anita Lavorgna

a.lavorgna@ soton.ac.uk

Maurizio Sajeva

maurizio.sajeva@unipa.it

1 Department of Sociology, Social Policy and Criminology, University of Southampton, 58 Salisbury Rd, Southampton SO17 1BJ, UK

2 Department of Biological, Chemical and Pharmaceutical Sciences and Technologies (STEBICEF), University of Palermo, Via Archirafi 18, 90123 Palermo, Italy 


\section{Introduction}

Plant crime is a major environmental problem that over the years has received attention in the area of conservation science (for example, Sajeva et al. 2013; Phelps and Webb 2015; Vaglica et al. 2017; Hinsley et al. 2017a, 2017b; Hinsley and Roberts 2018) and, more recently, also in the field of green criminology (Arroyo-Quiroz and Wyatt 2019; Lavorgna et al. 2020), a fast developing field of criminology focusing on the harms and crimes committed against the natural environment and non-human animals and plants living in it (Sollund 2019). It has been recognised that the illegal plant trade threatens and destroys numerous species and important natural resources, and can cause phytosanitary risks (Kaminski et al. 2012; Phelps and Webb 2015). Moreover, this type of illegal trade can hinder the rule of law, security, and good governance (UNODC 2016), fostering "environmental insecurity" (a term used in global environmental high politics to stress how the global illicit wildlife trade is both a source and outcome of biodiversity declines and social conflict, see Gore et al. 2016: 1). In recent years, the illegal plant trade is commonly believed to have grown with the expansion of globalisation and the commercialisation of cyberspace. An increasing number of studies have underlined how the internet has indeed facilitated supply and demand in this illegal market (Sajeva et al. 2013; Lavorgna 2014; Olmos-Lau and Mandujano 2016; Vaglica et al. 2017; CITES 2017, 2019; Interpol 2018).

Despite this increasing attention, in a criminological context in which the illegal trade in wild animals (and animal parts, such as ivory) has been increasingly under the spotlight over the last decade (see, among others, Wyatt 2013; Moreto and Lemieux 2015; Sollund 2015, 2019; Gore et al. 2016; van Hum 2018; Moreto and Pires 2018; van Uhm and Wong 2018; Wong 2019), plant crimes have so far been comparably under investigated, with the global illegal trade in plants continuing to receive relatively little attention - an issue that has been described as "plant blindness" (see Wandersee and Schussler 1999; Balding and Williams 2016; Margulies et al. 2018). The main exception to this blindness is timber, probably because of the superior monetary value of its trade, as well as the visible impact of logging on forested ecosystems which can prompt ecological justice-led attention (White 2008; Cao 2017; Margulies et al. 2019), giving visibility to the (lack of) health of the biosphere and to the conflictual relationship between social and ecological interests vs market liberalism and economic growth (Baxter 2005; White 2008).

Indeed, most efforts in academia, but also in policy making and consequently on law enforcement policies, are focused on other types of environmental crimes, such as the illegal trade in charismatic endangered animals and their derivatives (such as ivory from elephants), including online trading (see, among others, Moreto and Lemieux 2015; Sollund 2015; Felbab-Brown 2017; IFAW 2017; Alfino and Roberts 2018; van Uhm and Wong 2018; Wong 2019). While official definitions of "wildlife" encompass both animals and plants, in practice restrictive notions of what constitutes wildlife are often used: some researchers explicitly decide to focus on animal species for moral reasons (for instance, because they want to stress that animals' purpose in life should not be providing resources for humans, see Sollund 2019). Other studies do so probably due to unconscious bias, as our Anglo-European epistemological traditions tend to devalue plant life as evolutionarily beneath that of animal life (Heywood 2017; Margulies et al. 2018) — which can help to explain why, for instance, practices such as illegal, unreported, and unregulated (IUU) fishing are increasingly recognised as serious global environmental crimes threatening wildlife (Petrossian and Pezzella 2018; Miller et al. 2019b), while plant crimes are still overlooked (consider, for instance, The World Bank 2018). 
Despite the consensus that a better understanding of the characteristics of online illegal markets, and of the actors operating in them is a necessary starting point for any intervention to mitigate the problem (Economic and Social Council 2013; CITES 2019; Interpol 2018), there are still several research gaps on the role of the internet as a facilitator in the illegal trade of plants, and on its policing. This study furthers the path of inquiry by bringing together criminological and conservation science expertise (in line with the call for conservation criminology advocated by Gibbs et al. 2010) to provide an up-to-date analysis of the online illegal trade in endangered plants, and by identifying the main challenges to be addressed to improve its policing.

\section{Background}

Particularly over the last 60 years, the horticultural trade in exotic and wild plants has shown a strong increase (Sajeva et al. 2007; Novoa et al. 2017). Exotic and wild plants are harvested and traded all over the world, their parts and derivatives being used for a variety of purposes, including pharmaceuticals, food, and beauty products. Consider, for instance, that of approximately 30,000 plant species with documented medicinal or aromatic uses, about 3000 are found in international trade, more than $60 \%$ reportedly being harvested from the wild (Jenkins et al. 2018).

The global trade in plants is mostly regulated by the 1975 Convention on International Trade in Endangered Species of Wild Fauna and Flora (CITES). The CITES aims to control the trade of species which international commercialisation and over exploitation poses a serious threat to their survival, or could threaten survival in the future if not regulated (Young 2003; Lavorgna et al. 2018). The CITES lists in its Appendices three different levels of protection for endangered species, depending on the level of threat they are exposed to. More than 30,000 taxa of plants are included in the CITES Appendices (vs only about 5000 taxa of animals). CITES controls apply to plants and animals (both alive or dead) and to any readily recognisable parts and derivatives. This implies that parts of CITES-listed plants, including seeds, cuttings, and leaves are controlled. Products made from plants may also be subject to CITES controls. For instance, when a product contains a CITES-listed species, the product is subject to CITES controls. However, adjacent to the species listing in the Appendices, there may be annotations which include, or exclude, certain parts and derivatives (Sandison et al. 2002).

As anticipated in the "Introduction" section, over the past 15 years, the global trade in plants has received increased attention, with many studies focusing on its online features. Some of these studies are broader in scope, and by looking at online wildlife trafficking in general, have found specific anecdotal cases of plant trafficking (among the most recent studies, see IFAW 2017; Roberts and Hernandez-Castro 2017; Di Minin et al. 2018; Miller et al. 2019a). Wu (2007), for instance, in a study of wildlife trade on the Chinese language Internet, found evidence of adverts for live orchids, succulents, and Dendrobium extract. Similarly, in her study on online opportunities for illegal wildlife trade, Lavorgna (2014) found evidence of cacti trading, while Harrison et al. (2016) found limited evidence of the trade of cacti with hallucinogenic properties in the dark web.

Other studies, however, have focused more specifically on online plant trading, often by looking at specific taxa. Sajeva et al. (2013), for instance, monitored buyer-seller interactions over cacti plants on an Internet auction site. The authors suggested that only $10 \%$ of the plants 
traded were even potentially legal. Olmos-Lau and Mandujano (2016) assessed the online availability of a highly collectible cactus (genus: Strombocactus), demonstrating the existence of an active online trade of Strombocactus species and other species listed in the CITES without the necessary documentation. Hinsley et al. (2016) studied the trade of horticultural orchids via social media, using social network analysis to examine the ties between orchidthemed groups online, and finding evidence of trade in wild orchids, especially among English-speaking and Southeast Asian groups. Krigas et al. (2017), studying online trade in the endemic plants of Cyprus, found that vulnerable, endangered, and critically endangered taxa (according to the International Union for Conservation of Nature Red List of Threatened Species, a science-based inventory of the global conservation status of plant and animal species, see IUCN 2018) were also traded without the required CITES permits. Similarly, Vaglica et al. (2017) monitored online sales in five genera (including both CITES-listed and non-listed species) of succulent plant species endemic to Madagascar, revealing potential threats to wild populations.

The studies briefly surveyed to recognise the need to better monitor both online markets and social media (Hinsley et al. 2016; Krigas et al. 2017), but they do not specifically consider how to translate this need into implementable policies or linger on specific policing aspects. Nonetheless, there is consensus that online trading should become a priority for law enforcement improvement (Kretser et al. 2015; Hinsley et al. 2017a), and that interventions for capacity-building of enforcement personnel are needed to increase the quality of market surveillance for illegally traded wildlife (Lavorgna et al. 2020). Within this context, it is recognised that the policing of wildlife trafficking is still restricted and poorly resourced, with law enforcement agencies having limited training opportunities, often with no specific expertise on board to be effective in their job (Nurse 2015; CITES 2016a; Runhovde 2017). Overall, crimes against the environment have low priority on the law enforcement agenda: investigations are generally sparse, and consequences for offenders are often minimal (Fajardo del Castillo 2016; Hinsley et al. 2017a).

Our study focuses on the UK, which is considered a major importer in the area of wildlife trafficking and is a transit hub for trafficking to other regions (EU Commission 2016; UNODC 2016). It should be acknowledged, however, that there is also a general lack of reporting and prosecutions in the UK, especially for plant crime. As reported by the Wildlife and Countryside Link, a coalition of charitable organisations concerned with the conservation and protection of wildlife and the countryside (Link 2016), there is a worrying inability generally to produce information on how prevalent the offending is, and where the hotspots may be, with the consequence that a very limited amount of actual data is available for analysis and for identifying criminal trends.

\section{Main Law Enforcement Agencies and Other Relevant Bodies Dealing with Illegal Plant Trade in the UK and Beyond}

Before moving to the core of our study, we deemed it pertinent to provide a brief overview of the most relevant (governmental or otherwise public) actors, both at a national and international level, in curbing illegal plant trade.

In terms of enforcement agencies, in the UK, the National Wildlife Crime Unit (NWCU) provides a centralised capacity for intelligence collection and analysis, assisting in the prevention and detection of wildlife crime (for instance, by supporting criminal investigations 
where required, enhancing cross-border work and encouraging public and private sector involvement in combating wildlife crime). The NWCU has limited resources and staff (there are about 12 members in the team at full capacity), and focuses its efforts on specific issues considered to pose the greatest threat to the conservation status of a species, or that show the highest volume of crime, as advised by the Wildlife Crime Conservation Advisory Group (comprised of UK statutory nature conservation organisations, e.g. the Department of Agriculture; other statutory agencies, e.g. the Royal Botanic Gardens; Kew and relevant NGOs, e.g. TRAFFIC) (NWCU 2019). The Border Force is a law enforcement command body, working to secure the UK border by carrying out immigration and customs controls at ports and airports for people and goods (including plants and their derivatives) entering the country. This is achieved through customs checks carried out at ports and airports by Border Force officers, who have wide-ranging powers of entry, search, seizure, and arrest (UK Government 2019a). The Metropolitan Police (Met), which is responsible for the 32 London boroughs, also has a Wildlife Crime Unit, which is responsible for the enforcement of wildlife law and the implementation of initiatives to prevent wildlife crime. The Unit consists of a small team of five. In addition, each borough in the Met District has a wildlife crime officer (Metropolitan Police 2019).

At a national level, of particular relevance is the Partnership for Action Against Wildlife Crime (PAW), a multi-agency body comprising representatives of the organisations involved in wildlife law enforcement in the United Kingdom. PAW helps statutory and nongovernmental organisations work together to combat wildlife crime. It comprises a Secretariat which gives administrative support, a Steering Group, and Working Groups dedicated to specific issues, such as training or the use of forensic and specialist techniques to help solve wildlife crime (UK Government 2019b). With regard to plant issues specifically, the Royal Botanic Gardens, Kew, is the CITES Scientific Authority on flora, with the task of providing scientific advice on the CITES, helping develop governmental policies, and conducting research in support of the sustainable international trade of wild plant species; the CITES Management Authorities are the Department for Environment, Food and Rural Affairs (Defra), for policy, and the Animal and Plant Health Agency (APHA), for issuing permits and certificates (Kew 2019).

Moving into the transnational and international fields, it is also worth mentioning the role of Europol in facilitating operational information exchange and coordinating the activities of police, customs, forestry, and other law enforcement authorities from its member states (Europol 2019), and that of Interpol in ensuring that police around the world have access to the tools and services necessary to do their jobs effectively, by providing targeted training, expert investigative support, relevant data, and secure communications channels. With regard to environmental crime specifically, Interpol has the capability to lead global and regional operations, to shape strategies, to furnish environmental law enforcement agencies with access to tools and services, and to coordinate and develop international law enforcement best practice guides and other resources. For instance, the Interpol Ecomessage system represents an important tool for intelligence-led policing, offering a uniform intelligence data reporting system across many law enforcement agencies around the world. Another example is provided by the Environmental Compliance and Enforcement Committee (ECEC), which brings together senior officials and decision makers from all member countries in a forum to discuss strategies and practices, share expertise, and foster international cooperation (Interpol 2019). Again, at an international level, the United Nations Office on Drugs and Crime (UNODC) offers, among other things, research and analytical capacity, and support for field-based 
technical cooperation projects and training. Wildlife crime is considered highly relevant to the mandates of UNODC, given its transnational nature (UNODC 2019). Last but not least, the CITES Secretariat (administered by the UN Environment Programme) provides services to the CITES Parties and plays a coordinating and advisory role.

Among the tools used at the cross-border level, it is perhaps worth mentioning the European Union Trade in Wildlife Information eXchange (EU-TWIX), a tool operational since 2005, which was developed to facilitate information exchange and international cooperation between law enforcement officials across the EU. EU-TWIX consists of two complementary components, i.e. a database centralising data on wildlife trade seizures submitted by EU enforcement agencies and a mailing list allowing the quick sharing of information between designated enforcement officials on seizures and to exchange expertise on illegal wildlife trade matters.

\section{Methodology}

This study, developed in the context of the ESRC-funded project FloraGuard is based on information gathered during 15 semi-structured interviews on the characteristics of the market in illegal wildlife (plant), the actors involved, and policing and plant recovery strategies in the UK, and from a transnational perspective. Five interviews were carried out with team leaders and senior law enforcement officers in customs and wildlife crime units, while 10 interviews were carried out with relevant experts from NGOs and other institutions working on wildlife trafficking. Of these 15 interviews, 10 were directed at respondents operating in the UK, and, given the inherent cross-border nature of most illegal plant trade, five were conducted in transnational institutions working on wildlife trafficking (see Table 1). Further information was collected through consultations with FloraGuard project partners, namely the Royal Botanic Garden, Kew, and the UK Border Force CITES team, and also with our nonacademic project advisors ${ }^{1}$. Project partners and advisors also provided support in gaining access to some interviewees, while others were recruited through snowball sampling. All interviews took place, face-to-face or via Skype, from January to November 2018, with a couple of follow-ups taking place in July 2019. All interviews were audio recorded, professionally transcribed, and anonymised (in the following sections, respondents will be identified by numbers, e.g. INT 1). The research was approved by the University Research Ethics Committee (ERGO/ SSEGM/31264).

Although the research design was carefully prepared, there are some limitations: the number of interviewees and their geographical distribution is limited, which affects negatively the generalisability of the research. Considering the relatively small size in total population of relevant potential respondents for this study (which reflects the problem of "plant blindness", as discussed above, in policy making and law enforcement), the number of interviews carried out allowed the inclusion of representatives of (almost) all the main units, institutions, and organisations of interest. In addition, data gathered through the semi-structured interviews with key informants had the merit to allow the researchers to access current, rich, and detailed knowledge. Nonetheless, it is important to be careful in applying the conclusions of this study outside the context of this research (that is, the pre-Brexit UK). Further research focusing on a broader number of countries would certainly be useful to compare and possibly generalise our

\footnotetext{
${ }^{1}$ See http://floraguard.org/ for further details.
} 
Table 1 List of interviewees

\begin{tabular}{ll}
\hline Name & Background information \\
\hline INT 1 & Scientific Authority (UK) \\
INT 2 & (Senior) Law Enforcement (UK) \\
INT 3 & (Senior) Law Enforcement (UK) \\
INT 4 & NGO (UK) \\
INT 5 & Scientific Authority (International) \\
INT 6 & (Senior) Law Enforcement (UK) \\
INT 7 & Scientific Expert (UK) \\
INT 8 & International organisation \\
INT 9 & Scientific Authority (UK) \\
INT 10 & EU-TWIX consultant \\
INT 11 & (Senior) Law Enforcement (UK) \\
INT 12 & Scientific Authority (UK) \\
INT 13 & European Agency \\
INT 14 & Scientific Expert (International, support officer CITES) \\
INT 15 & Scientific Expert (UK) \\
\hline
\end{tabular}

findings. Furthermore, it is important to stress that the perspective in this article draws mainly on the perspective of law enforcement officials, scientific experts, and international NGOs and agencies; it would be important for future studies to include also perspectives of legal traders in plants.

The transcribed interviews were qualitatively analysed with the support of relevant software (NVivo 12). First, data was organised through a first pass review of the documents to identify meaningful and relevant passages of text along the following main codes: market characteristics, actors involved, organisational mechanisms, operational practices, current policing practices, CITES and its implementation, and existing and future challenges. Second, a thematic analysis of our data which involved a careful, more focused re-reading and review was carried out. In this process, codes and sub-codes were created and refined to uncover pertinent themes. The analysis was led by a criminologist in constant dialogue with a colleague expert in plant ecology in order to integrate insights and expertise from both criminology and conservation science, ensuring that appropriate conclusions were drawn from the data. The following section will present and discuss the results organised according to the main themes identified.

\section{Results and Discussion}

As it emerged clearly from all the interviews carried out, it is extremely important to distinguish between live specimens (LS) and derivative products (DP) when considering plant trade online, as these two main groups of products tend to follow very different patterns when it comes to online markets and behavioural patterns of the actors involved. Furthermore, it is important to recognise from the outset that the illegal market in plants is moved by two main diverse sets of motivations: first of all, the illegal plant trade is considered a low risk, yet very profitable, illegal market ("they see it generally as very low risk. [...] They were very happy to tell me openly, 'Yes, I’ve smuggled plants", INT 7; "So, it's lucrative illegal activity when the sentences are low and the profit is very high [and if] they were caught, they will pay, most likely, the fine", INT 13). Second, in the case of plant enthusiasts or collectors, passion and 
status are two key drivers ("they will be looking for specific things, you know, the rarer specimens, the more valuable, the ones that they can show off to their friends with", INT 6; "there is that species and it's very, very, very rare, as a botanical expert, I want to have it at home. I will buy it, I don't care what", INT 13). Having these core distinctions in mind can indeed help in clarifying some of the markets' characteristics and modus operandi presented in the following sections, as well as thinking more effectively about strategies for prevention and control.

\section{Online Markets' Characteristics and Trends}

All respondents identified a number of active online marketplaces for the illegal trading of plants, both generalist marketplaces (such as eBay, Amazon, and Alibaba), especially for DP and specialised ones, such as the webpages of nurseries, as well as social media platforms (among others, Facebook, Instagram, Pinterest, and Esty were all mentioned). In line with existing research on the topic (Harrison et al. 2016; Roberts and Hernandez-Castro 2017), respondents excluded the presence of significant plant trafficking in parts of the web not reachable by normal search engines - the so-called deep web. Indeed, as enforcement in even the clear web remains sparse, there is very little incentive for traders to move onto the dark web, where their pool of potential customers might be more limited. English was reported as a lingua franca in international online marketplaces (e.g. in the examples reported by a respondent, plants were advertised from the Far East in English), in line with existing research (Lavorgna 2014b; Kretser et al. 2015), even if Asian languages such as Vietnamese and Chinese are broadly used within diaspora communities.

In criminological research, online illegal markets are generally praised for the anonymity they offer (see, among others, Martin 2014). This feature, however, does not seem to be a key characteristic in illegal online market trading LS and DP. Particularly in the commerce of LS, most suppliers do not try to hide who they are, only one interviewee reporting suppliers using fake names. Of course, other types of precautions are taken to minimise the (low, but still existing) risks of exposure. Typically, once initial contact with a buyer has taken place, the sale goes "from being visible to invisible" (INT 11), meaning that the conversation is moved into more private settings, such as via email or by phone. Newcomers tend to feel safe online, but they become more cautious with experience ("if they do it for a long time they will gradually get smart to the fact that they have to use different terms", INT 2). Risk is also minimised by the use of camouflage or concealment techniques, such as hiding illegal LS among other species that can be traded legally, or using fake labels for DP. The so-called specimen laundering (INT 14) - i.e. if some CITES-protected ornamental plant, for instance, resembles one that is not listed - is commonly used. However, to mitigate this problem, Appendix II also includes species which are difficult to differentiate from those threatened, although they themselves might not be at risk of extinction (termed "look-alike" in the CITES) (Sajeva et al. 2007). Examples of look-alike listing are Cactaceae and Cycads, which are listed as families (Rutherford et al. 2013; Sajeva et al. 2012).

While the market in DP tends to be a bigger, more impersonal market, the market in LS being often closely connected to collectors' subcultures - is more easily affected by personal agendas and motives. For instance, alongside sales, it is common to encounter bartering and swaps among collectors. There are also important social engineering aspects, being mostly to do with how customers are targeted. For example, to borrow the words of one respondent, in the case of collectors, it is often about "befriending your customers before making them your 
customer" (INT 2), and then showing them pictures of the live plants they have themselves, and offering to procure them something similar ("And if you're a collector of orchids you're going to do that because you want the best and you want the one that looks most like a wild orchid would have grown and that kind of things", INT 7). Those smuggling illegal LS, little by little, get a reputation for doing so (in the words of one respondent, "[it is] like drugs in a university, everyone gradually learns who the person to go to is", INT 2). Interestingly, the LS market was described by one respondent as a "vindictive trade" (INT 3). With reference to a case involving rare LS, listed in Appendix I, the interviewee explained how in collectors' networks, certain traders are not afraid of "stabbing others in the back because that increases their commercial footprint then and the rivals [are taken] out of the market for a while", for instance by reporting them to Crimestoppers (a community programme, active in certain countries, which allows people to provide anonymous information about illegal activity).

Online plant markets, as many other online markets, can offer the opportunities for fraudulent activities, hence becoming "lemon markets", that is markets which exhibit asymmetric information, as buyers are unable to distinguish the quality of goods or easily identify potential rip offs (Akerlof 1970; Franklin et al. 2007) ("sometimes they say, 'I have a very, very rare orchid coming from Thailand,' but, basically, those are the orchids that you can be in the flower shop on every corner, you know", INT 13). Particularly in the case of collectors, if the attempted purchase is intentionally illegal, vendors and buyers cannot turn to the traditional enforcement and protection system should, for instance, a payment not be received or a product be substandard.

A couple of respondents reported how they had observed, over the last few years, some long-term changes to the market due to the ageing of certain major collectors. For instance, according to one interviewee, the (offline) illegal market in cacti, which was once prominent in the UK, has become less important as many large collectors have died or given their collections away (with many species being difficult to trade, as collections might be preCITES, which is not always easy to prove), while new generations are likely to be more active online. Other reported changes to the market are mostly short- and middle-term, and depend on changing hypes and trends. For instance, a couple of interviewees referred to a significant increase of the international trade in Hoodia (a species originating in Southern Africa) after this genus was reportedly endorsed by Oprah Winfrey as an appetite suppressant, to the point that the genus had to become CITES-listed. Another interviewer was expecting to see an increase in the illegal trade of DP used in Korean cosmetics; skincare having received much international attention in the last few years. With regard to the collectors' subculture per se, changes in online market trends for specific taxa can be observed when a major plant festival or show is approaching, or when a new species is discovered, as the element of novelty entails a high commercial value of the "new" plant (INT 14, for instance, reported the presence of a "strong interest for newly described species especially in cacti"; while INT 3 had recently seen on sale online the picture of a newly discovered specimen, and commented "that one has not even got a name so how can that be imported legally?"). For some collectors, collecting a specimen from the wild for their personal conservatory or garden is not to be considered as poaching, as they are not doing it to sell plants for a profit - especially when it comes to a "must have" plant. In a way, some collectors seem to rely on what we might consider techniques of neutralisation - that is, rationalisation offenders use to convince themselves that it is admissible to transcend dominant norms of conduct and commit deviant behaviour (Sykes and Matza 1957) - to deviate and justify their deviation from the environmentally responsible norms of conduct. For instance, reportedly, many collectors "deny the injury" as they look after and 
bread the poached plants with care, or "deny the responsibility" as in their view any responsibility should be limited to the vendor (Lavorgna et al. 2020).

\section{Social Organisation of the Suppliers}

Regarding the social relationships among the parties involved in illegal trade, we can distinguish between buyers and sellers who interact (1) solely through online forums or marketplaces, (2) by relying on online forums or marketplaces as a base, the interaction being further developed offline, (3) through offline social contacts, online interactions being used to further discuss the shared interest in plants. Hence, as explained by one respondent, it is not unusual to have both "people who just met online, and who probably only know themselves by their usernames", and "regional groups" (INT 5) formed by people who are likely to also hang out together offline in plant-related events such as exhibitions.

These latter are mostly collectors. Some of them are occasional smugglers: if they have the chance to go into a certain country of origin to collect a wild specimen, they might retain it for themselves, or they might already know the customer without advertising online. If an online advertisement is placed, this generally occurs in closed social media pages (which are not reachable by standard law enforcement monitoring or investigation) viewed by those in their social circle. Indeed, law enforcement agencies in the area of illegal wildlife trade are not legally permitted to access what is not available to them through the open webpages unless they obtain separate authority, such as a search warrant, which is very hard to obtain for this type of illegal activity (Lavorgna et al. 2020, details to be added after peer review).

In the case of LS, particularly when the core actors involved know each other offline, there seems to be much more vigilance and suspicion when dealing with outsiders. The network of contacts is carefully constructed. As explained by INT 5, "you have to know one person, and if this person introduces you, then you are in". Newcomers in the market have a hard time at the beginning: "the problem is, for them, [that] nobody really trusts you, nobody really knows you, whether you have really the genuine or you just offer something that you've seen on a website, like a picture, and then you... if I order that, then you're going to send me, I don't know, some of the regular type of cacti and things like that" (INT 13).

Most of the major suppliers ("competent illegal providers", as defined by INT 13) are highly professional and tend to be active for a long time in the market. Illegal wildlife trade is their main source of income ("they'll do it as a career", INT 2) and can often be described as "wholesale. I found people selling Dendrobium plants by the kilogram" (INT 7). Sometimes, these professional smugglers obtain citizenship of the country of origin where they spend most of their time and from where they do not risk being extradited should they be caught. Besides these professional actors, however, are occasional smugglers, generally individuals "who were just doing this as, sort of, a hobby, almost. So, they would go out and collect plants at the weekend, and then just sell on the off plant one at a time" (INT 7). As reported consistently by interviewees, the actors involved in smuggling tend to specialise in specific taxa (often depending on their country of origin and the subsequent smuggling route). An exception to this is the traders who have no particular area of specialisation but are simply re-sellers: they "buy things to resell them at a profit online, they simply make a nice website [...] and then when a person searches for Hoodia they show up at the top for that and a gajillion other products. And they don't have the actual Hoodia in stock, they're just resellers so when you place your order then they go out and find Hoodia for you" (INT 8). From a demographic perspective, interviewees agreed that plant smugglers are very diverse (especially in online 
trade, which opens the way to new actors), and therefore it is difficult to profile them; moreover, the age group is particularly diverse, with people from their 20 s to their 70 s (INT 3 ).

In illegal plant trading, the degree of organisation of the actors involved is very variable, ranging from individuals to (more or less structured) criminal networks with a certain degree of sophistication and preparation. INT 8, for instance, reported the essential role of "fixers" or "brokers" connecting the African and Asian routes by offering a network of contacts and logistics equipment (e.g. vans or taxis) to move the products before they reached the place from where they were going to be shipped internationally. Organised crime is generally not present, with the exception of some organised crime groups from the Far East using the international (underpriced) sale of many products, including CITES-listed specimens, as a way to launder money. Plant smuggling in general was linked by four respondents to cases of money laundering, tax evasion, and counterfeiting (especially in cases pertaining to the illegal trade of derivative products), as well as corruption (e.g. to obtain export permits). It should be underlined that organised crime was indeed mentioned as a key player by a couple of interviewees, but from the context, it was pretty clear that the term was used in a nontechnical way, as a synonym of criminal network ("you move from those individuals that are just making the purchase for themselves through the [....] plant enthusiasts through to the serious collectors [...] to, you know, the organised crime groups", INT 3). In most cases, different types of organisation reflect the different type of trade considered: the illegal horticultural trade is mostly run by individuals; DP (such as nutritional supplements) are often dealt with by companies. After all, as explained by one respondent, some of these companies "are very shady and probably would fall into the criminal section as well, but there we do have some kind of company structure, because you have a supplement that has to be produced somewhere, while with a wild plant you just have to dig it up and sell it" (INT 5).

Even if the social organisation of the suppliers, as we have seen, is very variable and context-dependent, it is essential to trace it to shed some light on the forms and structures illegal traders might take - especially in internet-facilitated activities, considering that the study of criminal groups and activities in cyberspace is still in its infancy. The social organisation approach, furthermore, has the additional merit to take into consideration also the social environment in which suppliers operate, allowing us to interpret the various organisational structures observed as the product of overlapping and interrelated social relationship that act as an information centre and a resource for those who need a specialised service (Potter 1994). After all, (criminal) organisations exist to deal with the dynamics of their reference markets and emerge as a response to the opportunities and challenges posed by their environment.

\section{CITES Awareness}

As regards non-compliance with legal requirements, the awareness of having done something illegal can vary. Respondents were overall concurrent in stressing how, in the case of collectors and other expert sellers or buyers, they had knowledge of the legal requirements, or at least of the fact that they (might) need permits and certificates. Three interviewees mentioned cases in which researchers, or otherwise well-known experts were involved in illegal trade, and another couple of respondents stressed how legal requirements are often discussed in specialised forums. Indeed, there were proxy indicators of illegality that an average connoisseur would easily recognise, such as "You can see from a plant whether it has been artificially propagated or not, the types of plants that they are trading they are plants that take like between on average 
100 years to get to the size that they are so they are obviously wild plants" (INT 14). Similarly, specialised importers ought to be aware that certain LS and DP need specific permits, or that they are not allowed - for them, it is a matter of due diligence. If they import illegally, this is generally linked to unfair competition practices: importing regularly involves costs and limitations, and by contravening legal requirements, they will have an edge on their competitors.

The buyers at the end of the trade chain or less specialised importers (especially when it comes to DP or finished products), however, might not have a clue about the legal requirements ("a lot of people don't even think, you know, about plants being on CITES, a lot of people only think of the animals", INT 9). This form of naivety or "non-compliance through ignorance" (INT 11) is particularly problematic, as it creates a significant burden for customs units (even if this type of illegality, in many cases, does not cause any meaningful environmental or social harm). Furthermore, such naivety is difficult to assuage, due to the complexity of CITES and its national implementations, which often requires specialised knowledge to properly navigate. Consider, for instance, the situation effectively described in the following snippet:

"I think what's happening right now is that we have a lot of online [...] mass distributors, internet distributors of [...] all sorts of products and people order these things and these people that are shipping this stuff have no knowledge of CITES, they just procure stuff from domestic sources and they ship it internationally" (INT 8).

Either way, these findings suggest that there is currently a failure in the existing system in educating buyers and in raising their awareness to the issue of "illegal because endangered"; conservation-related aspects seem to be overlooked in buyers' decision making. Further research analysing the motivations and the discourses of buyers/importers would be welcomed to complement the interviewees' views.

\section{Facilitators and Contribution to Success}

We have already seen above how the illegal market in plants can at times be facilitated by actors in the criminal or grey economy, especially in the more sophisticated cases, where the support of a (more or less criminal) network might be needed. In most cases, however, this illegal trade is enabled by facilitators in the legal economy, such as plant nurseries, fulfilment houses (handling with warehousing and shipping for e-commerce companies), and international platforms for business-to-business trade. These latter have been described as an "outlet channel" for the illegal trade of expensive plant derivatives, with several actors (ranging, for instance, from wholesalers in the countries of origin or transit, to cross-border retailers, to local herbalists in the countries of destination) involved in various ways along the trade chain before the final product reaches the intended customer (INT 4).

However, cyberspace was consistently identified by all respondents as a key facilitator for the illegal market in plants. Consistent with what has been emphasised in the academic literature on online wildlife trade, the main criminogenic opportunity identified by all respondents in online markets was that of having facilitated supply and demand, especially with regard to niche markets (Lavorgna 2014). Some respondents, however, stressed how the Internet allowed international suppliers to significantly cut costs, not only increasing the profitability of the market, but also making some products more accessible to buyers (INT 11). It also made it harder to prove criminal intention and to build a body of evidence for filing a legal case, as receiving something by post poses a very low risk of incrimination ("By the 
time maybe somebody has investigated something online maybe the site disappears. [...] With the internet it's quite difficult because it can be so fleeting", INT 9).

\section{Lack of Comprehensive and Reliable Datasets}

A major issue reported by respondents concerned the difficulty in obtaining accurate data and reliable estimates of how much is traded online (in line with the inconsistent crime recording problems reported by Chan et al. 2015 and Runhovde 2017). Existing databases on plant trade or wildlife trafficking (such as the World WISE database compiled by the UN or the EUTWIX database, both based on data reported by member states), indeed, are only as good as the data that individual countries provide, and, in any case, may not distinguish between online and offline trade. Unsurprisingly, the absence of trust among interested parties (which is often fuelled by lack of legal harmonisation and long-standing organisational attitudes to law enforcement) seems to be a key obstacle for integrated cross-agency intelligence, as information is not always shared on an effectual, time-sensitive, and consistent basis (Benyon 1994; Gerspacher and Dupont 2007).

Most intelligence developed and used by the organisations of which the interviewees were part was open-source (OSINT). Despite its merits (for instance, it is commonly recognised as a resource-effective approach, and data obtained through it can be shared easily and legally with anyone), OSINT also has major limitations, in primis, the risk of information overload, cognitive biases, and the potential poor quality and credibility of its results (Weir 2016). Indepth analyses are often available only for ad hoc species, with external resources available for a full consultancy on specific taxa and their trade. Most of the responses provided by the interviewees were therefore based on anecdotal data. However, only a minority of interviewees were careful in drawing general conclusions from their own experience (e.g. "I mean this is not based on any data whatsoever, this is just what I've seen over the years", INT 15), which may suggest an over reliance on data that are by their nature of difficult generalisability.

\section{Policing Plant Crimes}

It was quite clear from the answers received that plants are barely considered in mainstream policing. This lack of care is a complex problem, requiring specific solutions, not only because it neglects the environmental and phytosanitary risks presented in the "Introduction" section, but also because it produces feelings of "frustration" in those active in curbing the illegal trade in LS and DP (INT 11), potentially hindering their ability to do their job effectively. As one interviewee put it, "there's not an understanding that you might be trading species that are endangered or that are covered by the convention, there's not even a consideration to [the fact of plants are protected by CITES]" (INT 14) Other respondents passionately explained, "people are obsessed with animals and I don't know why they cannot view the other species with equal measure" (INT 15); "nobody seems to acknowledge that you chop down [plants] everything else disappears as well, you know? And it's because all these nice fluffy animals are dying in Africa just keep everybody's attention [...] obviously, this is definitely not assigned to my name (laughing), but I had an official [saying] that plants are not included under the definition of 'wildlife' so, that just shows you, you know..." (INT 11). In line with the literature denouncing "plant blindness", plant crimes are indeed considered as victimless crimes, which receive attention only when there is sufficiently direct impact "on human beings and their lives as well" (INT 13). This lack of care is closely linked to the lack of political will 
to address plant crime, which is perceived as not worthy of much attention and resources ("it depends on what ministers want. I mean obviously, this is a political issue, you know. If they say they want to focus on ivory, they want to focus on ivory [...] I mean, they are told by their bosses, $[\ldots]$ they have targets they have to hit", INT 15).

One effect of the overlooking of illegal plant trading is that only a handful of cases are fully investigated in the UK each year, as reported by the law enforcement interviews. Ad hoc operations, such as the Interpol-led Operation Pangea - an annual international field operation targeting the sale of counterfeit and illicit medicines and medical products, including DP, over a week - can certainly be useful in raising public awareness but, as stressed cynically by one respondent, they are not particularly effective in the long term ("[they'll] switch on to looking for tablets and find loads of tablets (laughs) but the rest of the year it's sailing through, you know?", INT 11).

When a DP or LS is confiscated, a common practice is that of "seize and report": the buyer is notified that the product has been seized, and if he/she replies that they were not aware they had been buying something illegal, the seizure is the end of the matter - an approach that does not seem to be very effective for either general or individual deterrence when it comes to unscrupulous sellers. Furthermore, even when a product is seized, it might be very difficult for the buyer to get their money back from the seller. Despite these limitations, as reported by an interviewee from Border Force, the number of seizures is increasing (1085 in 2018, 56\% of which were plants- or timber-related).

Overall, lack of resources (both financial resources and manpower) were mentioned by all respondents, who felt "pulled too many ways" (INT 15), ending up by not having time to focus on plant trade and online markets. These constraints could seriously jeopardise the capability of officials in doing their work. As reported by one respondent, for instance:

"I do remember [...] we've seen [specimen] on a forum, it was sold within 12 hours. [...] So, if you want to stop it, if you want to find the plant, you really have to be quick. [...] If someone posts something on a forum with their username, it might be very challenging to find out what is actually happening, where he's offering it, $[\ldots]$, there needs to be the manpower to go and look. [...] Because if you would like to go to a prosecution or to a court case, you need the proof, and very often, you need the plant for that" (INT 5).

Lack of resources also had a detrimental impact on training. Training on CITES-related matters did occur but was considered insufficient to have a real impact on the capabilities of law enforcement officers ("I've had five days training in CITES in 18 years", INT 11). At the end of the day, the take-home point of the training session was "to keep the[ir] eyes open. It's just to recognise that, you know, plants are smuggled, plants are in anything and everything. So, don't just think about live plants, think about parts and derivatives", and to know how to reach the few experts in national law enforcement ("the thing I say to them, the most important thing you do today is to take my contact details or know that [same] is available", INT 11). From the interviews with law enforcement officers, it was very clear that the existing system to counter illegal plant trade (and wildlife generally) works though the commitment of dedicated individuals, rather than because of proper planning and effective management (in line with Runhovde 2017). To counter plant trade effectively, an extremely high degree of specialisation is needed, something that cannot be picked up in a few days' training ("For enforcement officers, it's almost impossible to train them to the levels required to identify species levels at the border. [...] I think it's just experience", INT 11). Out of the 149 sea and airports of entry across the UK and overseas, Border Force only has two ports with dedicated units and inhouse experts (in Heathrow and Felixstowe, respectively, the UK's busiest airport and 
container ports). Experts, for instance, from Royal Botanic Gardens, Kew, can be consulted when needed, but this does not solve the problem of having only a few people in the country with the ability to identify illegal LS and DP, and who are mostly concentrated in the East of England. These experts, moreover, are often subject to a quick turnaround, despite working in a field where in-depth expertise is developed over many years, with a lot of on-the-job experience. Another impact on training, linked to the paucity of resources, is the lack of access to academic studies for most officers, who, as one respondent complained (INT 11), had difficulties in accessing academic research if they wanted to improve or update their knowledge on criminological or conservation science issues.

Because of this lack of specialisation, a primary policing challenge is being able to identify what requires law enforcement attention in the first place. Indeed, a traded LS or DP could be (1) legal; (2) illegal due to not complying with a CITES requirement, e.g. a permit (but otherwise the trade of that specimen would be legal); (3) illegal because collected from the wild, when this is not permitted (and when, in this latter case, not only is the trade illegal, but also entails environmental harm). For LS, this challenge mainly translates into being able to distinguish (often from its physical features) among wild plants and those artificially propagated (i.e. plantation grown). For DP, a solution to such challenges often entails analysis of the final product, but in order for this to take place, there has to be at least an informed intuition that something illegal is going on. Furthermore, even if forensic analysis is needed to properly identify the taxa (and consequently the illegality of a product), most places lack the research facilities to carry out this type of analysis, and in any case, the cost would often be over and above what has been seized - especially considering that most plants and derivatives are moved internationally in relatively small amounts. Furthermore, this approach might not always be feasible for multi-ingredient derivative products or for taxa that do not have a back-up reference collection, which is needed to determine whether a certain specimen comes from the wild or has been artificially propagated.

Another specific set of challenges refers to linguistic issues. First of all, especially when it comes to the illegal trade of highly protected species, specialised jargon tends to be used. Second, some online communication or labelling of DP is in languages unknown to the officers, such as Chinese, Vietnamese, Thai, or Russian. Even if, at the European Union level (and so, at the time of writing, also for the UK), there are labelling requirements for imported goods, these can be eluded: "you'll have a plastic wrapper, product name, usually in Chinese, and they might stick an English label over the top [...] And if they know what they're doing the ingredients on the back are either altered or the one that matters isn't there" (INT 11).

Online monitoring is consistently recognised as an investigative need for intelligence-led policing to identify high-risk shipments or trafficking trends, but due to lack of time and manpower, it is still considered a "side job" (INT 13), and is not done in a consistent way. Law enforcement officers lamented that they did not have the means to be proactive ("we tend to end up answering calls rather than chasing up, really", INT 6).

Interestingly, it was the threat of Brexit, and most of all, the uncertainties surrounding it, that was mentioned by four interviewees as the biggest challenge on the horizon, especially regarding the potential sudden increased strain on the workload ("all could change, if we leave without a deal anything from Italy, Poland, Czech Republic [will] need CITES documents so technically then they will be smuggled so that opens a whole new picture", INT 3).

Overall, these findings on plant crimes policing are in line with the findings of other wildlife crime research, which stressed that there are longstanding problems in identifying the extent of this type of environmental crime, issues with investigation and prosecution (with 
wildlife policing being very limited and poorly resourced), and very low priority given to wildlife crimes in general within all policy discourses (Lemieux 2014; Fajardo del Castillo 2016; Runhovde 2017), making wildlife crime (including illegal online trades in plants) a high-profit, low-risk criminal business (Hinsley et al. 2017a).

\section{Conclusions and Recommendations}

In this study, we have identified a number of online markets active in the illegal sale of LS and DP discussed their more recent trends, and presented the main strategies used by suppliers to build and maintain their customer base, while minimising their risks. We have also seen the importance to distinguish among buyers' motivations, as they entail diverse sets of markets' characteristics and modus operandi, as well as to reflect on the varying social organisation of the suppliers, as these aspects carry important consequences in terms of crime prevention and control. Furthermore, we have discussed a range of difficulties in tackling plant crimes, due to the lack of regulatory awareness, of comprehensive and reliable datasets, and of sufficiently trained and specialised law enforcement agents.

Many of the challenges presented in this study are not unique to plant trading; they are an unfortunate consequence of the fact that international commerce has developed faster than our international capacity to regulate and monitor it, boosted in exponential ways by the commercialisation of cyberspace. While recognising the need for long-term solutions to prevent the illegal trade in plants (and especially the harvesting of endangered plants) in the country of origin, the results of the interviews carried out suggest a number of short- and medium-term cost/effective interventions which, if properly implemented, would have a good potential in preventing or disrupting the illegal marketplace, mitigating the problem.

First of all, we should recognise that there are different levels of illegality/seriousness in the illegal plant trade; in the legal framework, we should hence distinguish in a clearer way between those acts of illegality that are nothing more than "administrative offences" (where a permit is accidentally missing), and those acts resulting in potentially serious environmental harm. By relying on this distinction, a focus on the second category would further align CITES with the Convention on Biological Diversity (CBD) - a pathway already initiated (Cooney 2001; CITES 2016b).

It should be born in mind that CITES provides a framework (to be enacted by domestic legislation) to regulate international trade, thus affecting the daily business of anyone dealing with LS and DP, even on an occasional basis. The CITES framework, however, has vulnerabilities that can create unintended criminal opportunities (Lavorgna et al. 2018), and particularly by regulating rather than prohibiting the trade of LS and DP that are often difficult to recognise is partially inadequate as enforcement tool. Overall, CITES is extremely complex and can be difficult to navigate, even for experts ("[plant trafficking] a subject that everybody avoids [in my organisation] because it's a huge subject", INT 13). In order to facilitate compliance, we recommend that national CITES authorities should make flux diagrams readily available to facilitate traders' and buyers' comprehension of what they need to do, step-by-step, to comply with the legal requirements, and to have a clearer, upfront idea of the costs involved in CITES documentation.

Raising awareness is certainly important, but a conversation also needs to be taken forward as to whether existing awareness-raising campaigns have been targeted in the right direction. For instance, trade associations and business companies with a vested interest in certain plants 
(such as those in the cosmetics sector), as well as plant show organisers and collectors' associations, need to be made aware and even trained in a more systematic way, while this approach is currently only occasional and inconsistent. We also suggest the need to emphasise not only the environmental damage relating to the illegal trade in endangered plants, but also, first and foremost, the health and phytosanitary problems, as a way of increasing the risk perception for this type of illegal activity and sensitising the general public to the issue. Also, botanical gardens could have an enhanced role in this context, being used to proactively promote public sensitivity on plant crimes, ex situ conservation (Faraji and Karimi 2020), and legal propagation of endangered species (see, for instance, Badalamenti et al. 2016) in a way that might resemble the approach of certain zoological gardens.

The need for law enforcement bodies to constantly interact with experts in plant ecology is inescapable, if only to facilitate the visual identification of specific taxa, and to be kept up-todate with the discovery of new species, changes in the jargon, and to quickly identify emerging hypes. Each port of entry should have constant access to a small team of professional experts (e.g. naturalists and biologists) within geographical reach, who can side with custom officers when needed. The existing training models should be backed up by a mentoring model, allowing the few officers with expertise built up over the years to pass it on, little by little, to the next generation. Besides the specialisation of police and custom officers, we recommend specialised training to be provided to lawyers and judges, in order to increase the chances of successful prosecution for wildlife crimes.

Regarding specifically the online features of the market, innovative approaches piloted in other online markets could be adapted to the online market in wildlife, such as attempts to "lemonise" the market to create quality uncertainty, and to increase mistrust between buyers and sellers (Hutchings and Holt 2015). Finally, in order to improve the evidence-based policies, we also suggest better access for researchers (subject to vetting) to non-sensitive data, such as those transmitted through EU-TWIX, as this would allow better identification of patterns and changing trends in the market, and hence better tailoring of effective responses.

\section{Compliance with Ethical Standards}

The research was approved by the University Research Ethics Committee (ERGO/ SSEGM/31264).

Open Access This article is licensed under a Creative Commons Attribution 4.0 International License, which permits use, sharing, adaptation, distribution and reproduction in any medium or format, as long as you give appropriate credit to the original author(s) and the source, provide a link to the Creative Commons licence, and indicate if changes were made. The images or other third party material in this article are included in the article's Creative Commons licence, unless indicated otherwise in a credit line to the material. If material is not included in the article's Creative Commons licence and your intended use is not permitted by statutory regulation or exceeds the permitted use, you will need to obtain permission directly from the copyright holder. To view a copy of this licence, visit http://creativecommons.org/licenses/by/4.0/.

\section{References}

Akerlof, G. A. (1970). The market for 'lemons': quality uncertainty and the market mechanism. The Quarterly Journal of Economics, 84(3), 488-500.

Alfino, S., \& Roberts, D. L. (2018). Code word usage in the online ivory trade across four European Union member states. Oryx (online first). 
Arroyo-Quiroz, I., \& Wyatt, T. (2019). The illegal wildlife trade between Mexico and the European Union. International Journal of Crime, Justice and Social Democracy (forthcoming).

Badalamenti, O., Carra, A., Oddo, E., Carimi, F., \& Sajeva, M. (2016). Is in vitro micrografting a possible valid alternative to traditional micropropagation in Cactaceae? Pelecyphora aselliformis as a case study. SpringerPlus, 5(1), 1-4.

Balding, M., \& Williams, K. J. (2016). Plant blindness and the implications for plant conservation. Conservation Biology, 30(6), 1192-1199.

Baxter, B. (2005). A theory of ecological justice. London: Routledge.

Benyon, J. (1994). Policing the European Union: the changing basis of cooperation on law enforcement. International Affairs, 70(3), 497-517.

Cao, N.A. (2017) Timber trafficking in Vietnam. Crime, security and the environment. London: Palgrave.

Chan, H. K., Zhang, H., Yang, F., \& Fisher, G. (2015). Improve customs' systems to monitor global wildlife trade. Science, 348(6232), 291-292.

CITES (2016a) Wildlife crime. What are the challenges to effective law enforcement? Available at: https://cites. org/prog/iccwc.php/Wildlife-Crime.

CITES (2016b) CITES and CBD Parties jointly prepare for key global meetings. Available at: https:// w w w. c i t e s.o r g/e n g/n e w s/p r/ CITES_and_CBD_Parties_jointly_prepare_for_key_global_meetings_13092016.

CITES (2017) CITES-listed medicinal plant species. PC23 Inf.10. Available at: https://cites. org/sites/default/files/eng/com/pc/23/inf/E-PC23-Inf-10.pdf.

CITES (2019) Report of the Secretariat and Report of the Standing Committee. CoP 18. Doc 33.1 and Doc 33.2. Available at: https://cites.org/eng/cop/18/doc/index.php.

Cooney, R. (2001). CITES and the CBD: tensions and strategies. RECIEL, 10(3), 259-267.

Di Minin, E., Fink, C., Tenkanen, H., \& Hippala, T. (2018). Machine learning for tracking illegal wildlife trade on social media. Nature Ecology \& Evolution, 2, 406-407.

Economic and Social Council (2013) Resolution adopted by the Economic and Social Council on 25 July 2013. E/RES/2013/40. United Nations.

EU Commission (2016) EU action plan against wildlife trafficking. Available at: http://eur-lex.europa.eu/legalcontent/EN/TXT/?uri=COM:2016:87:FIN.

Europol (2019) Environmental crime. Available at: https://www.europol.europa.eu/crime-areas-andtrends/crime-areas/environmental-crime/illicit-trafficking-in-endangered-animal-species.

Fajardo del Castillo, T. (2016). The European Union's approach in the fight against wildlife trafficking: challenges ahead. Journal of International Wildlife Law and Policy, 19(1), 1-21.

Faraji, L., \& Karimi, M. (2020). Botanical gardens as valuable resources in plant sciences. Biodiversity and Conservation, 1-22.

Felbab-Brown, V. (2017). The extinction market: wildlife trafficking and how to counter it. London: C. Hurst \& Co Publishers.

Franklin, J., Paxson, V., Savage, S., \& Perrig, A. (2007). An inquiry into the nature and causes of the wealth of internet miscreants. ACM Conference on Computer and Communications Security (CCS)

Gerspacher, N., \& Dupont, B. (2007). The nodal structure of international police cooperation: an exploration of transnational security networks. Global Governance, 13, 347-364.

Gibbs, C., Gore, M. L., McGarrel, E. F., \& Rivers, L. (2010). Introducing conservation criminology. Towards interdisciplinary scholarship on environmental crimes and risks. The British Journal of Criminology, 50(1), 124-144.

Gore, M. L., Lute, M. L., Ratsimbazafy, J. H., \& Rajaonson, A. (2016). Local perspectives on environmental security and its influence on illegal biodiversity exploitation. PLoS One. https://doi.org/10.1371/journal. pone.0150337.

Harrison, J. R., Roberts, D. L., \& Hernandez-Castro, J. (2016). Assessing the extent and nature of wildlife trade on the dark web. Conservation Biology, 30(4), 900-904.

Heywood, V. H. (2017). Plant conservation in the Anthropocene-challenges and future prospects. Plant Diversity, 39(6), 314-330.

Hinsley, A., Lee, T. E., Harrison, J. R., \& Roberts, D. L. (2016). Estimating the extent and structure of trade in horticultural orchids via social media. Conservation Biology, 30(5), 1038-1047.

Hinsley, A., Nuno, A., Ridout, M., St John, F. A. V., \& Roberts, D. L. (2017a). Estimating the extent of CITES non-compliance among traders and end-consumers. Lessons from the global orchid trade. Conservation Letters, 10(5), 602-609.

Hinsley, A., de Boer, H. J., Fay, M. F., Gale, S. W., Gardiner, L. M., Gunasekara, R. S., Kumar, P., Masters, S., Metusala, D., Roberts, D. L., Veldman, S., \& Phelps, J. (2017b). A review of the trade in orchids and its implications for conservation. Botanical Journal of the Linnean Society, 186(4), 435-455.

Hinsley, A., \& Roberts, D. L. (2018). The wild origin dilemma. Biological Conservation, 217, 203-206. 
Hutchings, A., \& Holt, T. J. (2015). A crime script analysis of the online stolen data market. British Journal of Criminology, 55, 596-614.

IFAW. (2017). Disrupt: wildlife cybercrime. London: International Fund for Animal Welfare.

Interpol (2018) Global wildlife enforcement. Strengthening law enforcement cooperation against wildlife crime. Lyon: Interpol.

Interpol (2019) Environmental crime. Available at: https:/www.interpol.int/en/Crimes/Environmental-crime.

International Union for Conservation of Nature (IUCN) (2018) IUCN red list of threatened species. Summary statistics. Available from: https://www.iucnredlist.org/resources/summary-statistics.

Jenkins, M., Timoshyna, A., \& Cornthwaite, M. (2018). Wild at home: an overview of the harvest and trade in wild plant ingredients. Cambridge: TRAFFIC.

Kaminski, K., Beckers, F., \& Unger, J. G. (2012). Global internet trade of plants - legality and risks. Bullettin OEPP, 42(2), 171-175.

Kew (2019) UK Cites Scientific Authority for Flora. Available at: https://www.kew.org/science/ourscience/science-services/UK-CITES.

Kretser, H. E., Wong, R., Roberton, S., Pershyn, C., Huang, J. M., Sun, F., Kang, A., \& Zahler, P. (2015). Mobile decision-tree tool technology as a means to detect wildlife crimes and build enforcement networks. Biological Conservation, 189, 33-38.

Krigas, N., Menteli, V., Chrysanthou, P., \& Vokou, D. (2017). The electronic trade in endemic plants of Cyprus through the internet. Plant Biosystems, 151(3), 387-393.

Lavorgna, A. (2014). Wildlife trafficking in the internet age. Crime Science, 3(5), 1-12.

Lavorgna, A., Rutherford, C., Vaglica, V., Smith, M. J., \& Sajeva, M. (2018). CITES, wild plants, and opportunities for crime. European Journal on Criminal Policy and Research, 24, 269-288.

Lavorgna A, Middleton SE, Pickering B and Neumann G (2020) FloraGuard: tackling the online trade in endangered plants through a cross-disciplinary ICT-enabled methodology. Journal of Contemporary Criminal Justice

Lemieux, A. M. (2014). Situational prevention of poaching. New York: Routledge.

Link (2016) Wildlife Crime in 2016. A report on the scale of wildlife crime in England and Wales. London and Cardiff: Wildlife and Countryside Link and Wales Environment Link.

Margulies, J.D., Hinsley, A. and Phelps, J. (2018) Illegal wildlife trade endangers plants — but few are listening. IUCN Blog. Available at: https://www.iucn.org/news/species/201810/illegal-wildlife-trade-endangersplants-few-are-listening.

Margulies, J. D., Bullough, L. A., Hinsley, A., Ingram, D., Cowell, C., Goettsch, B., Klitgård, B., Lavorgna, A., Sinovas, P., \& Phelps, J. (2019). Illegal wildlife trade and the persistence of 'plant blindness'. Plants People Planet, 1(3), 173-182.

Martin, J. (2014). Lost on the silk road. Online drug distribution and the 'cryptomarket'. Criminology and Criminal Justice, 14(3), 351-367.

Metropolitan Police (2019) Wildlife crime. Available at: https://www.met.police.uk/advice/advice-andinformation/wc/wildlife-crime/.

Miller, C., Pay, J. and Smith, J. (2019a) Detecting online environmental crime markets. Digital Dangers Report. Available at: https://globalinitiative.net/detecting-online-environmental-crime-markets/.

Miller, E. A., McClenachan, L., Yoshikazu, U., Phocas, G., Hagemann, M. E., \& Van Houtan, K. S. (2019b). The historical development of complex global trafficking networks for marine wildlife. Science Advances, 5(3), eaav5948.

Moreto, W. D., \& Lemieux, A. M. (2015). From CRAVED to CAPTURED: introducing a product-based framework to examine illegal wildlife markets. European Journal on Criminal Policy and Research, 21, 303-320.

Moreto, W. D., \& Pires, S. P. (2018). Wildlife crime. An environmental criminology and crime science perspective. Durham: Carolina Academic Press.

Novoa, A., Le Roux, J. J., Richardson, D. M., \& Wilson, J. R. (2017). Level of environmental threat posed by horticultural trade in Cactaceae. Conservation Biology, 31(5), 1066-1075.

Nurse, A. (2015). Policing wildlife: perspectives on the enforcement of wildlife legislation. London: Plagrave Macmillan.

NWCU (2019) UK National Wildlife Crime Unit. Available at: https://www.nwcu.police.uk/.

Olmos-Lau, V. R., \& Mandujano, M. C. (2016). An open door for illegal trade: online sale of strombocactus disciformis (cactacae). Nature Conservation, 15, 1-9.

Petrossian, G. A., \& Pezzella, F. S. (2018). IUU fishing and seafood fraud: using crime script analysis to inform intervention. The Annals of the American Academy of Political and Social Science, 679(1), 121-139.

Phelps, J., \& Webb, E. L. (2015). "Invisible" wildlife trades: Southeast Asia's undocumented illegal trade in wild ornamental plants. Biological Conservation, 186, 296-305. 
Potter, G.W. (1994) Criminal Organizations. Vice, Racketeering, and Politics in an American City. Prospect Heights: Waveland.

Roberts, D. L., \& Hernandez-Castro, J. (2017). Bycatch and illegal wildlife trade on the dark web. Oryx, 51(3), 393-394.

Runhovde, S. R. (2017). Taking the path of least resistance? Decision-making in police investigations of illegal wildlife trade. Policing: A Journal of Policy and Practice, 11(1), 87-102.

Rutherford, C., Donaldson, J., Hudson, D., McGough, H. N., Sajeva, M., Schippmann, U., \& Tse-Laurence, M. (2013). CITES and cycads a user's guide. Kew, London: Royal Botanic Gardens.

Sajeva, M., Carimi, F., \& McGough, N. (2007). The Convention on International Trade in Endangered Species of Wild Fauna and Flora (CITES) and its role in conservation. Functional Ecosystems and Communities, $1(2), 80-85$.

Sajeva, M., McGough, H. N., Garrett, L., Luethy, J., Tse-Laurence, M., Rutherford, C., \& Sajeva, G. (2012). CITES and cacti a user's guide. Kew, London: Royal Botanic Gardens.

Sajeva, M., Augugliaro, C., Smith, M. J., \& Oddo, E. (2013). Regulating internet trade in CITES species. Conservation Biology, 27(2), 429-430.

Sandison, M., Clemente, M., De Konig, J., Taylor, K., Groves, M., \& Sajeva, M. (2002). CITES and plants, a user's guide. Version 2.0. Kew, London: Royal Botanic Gardens.

Sollund, R. (2015). Wildlife trafficking in a globalised world: an example of motivations and modus operandi from a Norvegian case study. In F. Angelici (Ed.), Problematic wildlife. London: Springer.

Sollund, R. (2019). The crimes of wildlife trafficking. Issues of justice, legality and morality. Milton Park: Routledge.

Sykes, G., \& Matza, D. (1957). Techniques of neutralization: a theory of delinquency. American Sociological Review, 22(6), 664-670.

The World Bank (2018) The Global Wildlife Program knowledge platform 2016-2018: a Global Partnership on Wildlife Conservation and Crime Prevention for Sustainable Development. Available at: http://pubdocs. worldbank.org/en/106731546908148816/43567-GWP-Annual-Report-2018.pdf.

UK Government (2019a) Border Force. Available at: https:/www.gov.uk/government/organisations/borderforce.

UK Government (2019b) Partnership for Action against Wildlife crime. Available at: https://www.gov. uk/government/groups/partnership-for-action-against-wildlife-crime.

UNODC (2016) World Wildlife Crime Report. Trafficking in protected species. Vienna: the United Nations Office on drugs and crime.

UNODC (2019) Global Programme. https://www.unodc.org/unodc/en/wildlife-and-forest-crime/globalprogramme.html.

Vaglica, V., Sajeva, M., McGough, N., Hutchison, D., Russo, C., Gordon, A. D., Ramarosandratana, A. V., Stuppy, W., \& Smith, M. (2017). Monitoring internet trade to inform species conservation actions. Endangered Species Research, 32, 223-235.

van Uhm, D. P., \& Wong, R. W. Y. (2018). Establishing trust in the illegal wildlife trade in China. Asian Journal of Criminology, 14(1), 23-40.

Wandersee, J. H., \& Schussler, E. E. (1999). Preventing plant blindness. The American Biology Teacher, 61(2), $82-86$.

Weir, G. R. S. (2016). The limitations of automating OSINT: understanding the question, not the answer. In R. Layton \& P. A. Watters (Eds.), Automating Open Source Intelligence: Algorithms for OSINT. Syngress Publishing.

White, R. (2008). Crimes against nature. Environmental criminology and ecological justice. Milton Park: Routledge.

Wong, R. W. Y. (2019). The illegal wildlife trade in China. Understanding the distribution networks. London: Palgrave.

Wu, J. (2007). World without borders: wildlife trade on the Chinese-language internet. TRAFFIC Bulletin, 21(2), 75-84.

Wyatt, T. (2013). Wildlife trafficking. A deconstruction of the crime, the victims and the offenders. London: Palgrave.

Young, S. (2003). Contemporary issues of the convention on international trade in endangered species of wild Fauna and Flora (CITES) and the debate over sustainable use. Journal of international Environmental Law and Policy, 14(1), 167-189.

Publisher's Note Springer Nature remains neutral with regard to jurisdictional claims in published maps and institutional affiliations. 